Article

\title{
Self-Cleaning Ceramic Tiles Produced via Stable Coating of $\mathrm{TiO}_{2}$ Nanoparticles
}

\author{
Amid Shakeri ${ }^{1}$, Darren Yip ${ }^{1}$, Maryam Badv ${ }^{2}$, Sara M. Imani ${ }^{2}$, Mehdi Sanjari ${ }^{3}$ and \\ Tohid F. Didar 1,2,4,* (iD \\ 1 Department of Mechanical Engineering, McMaster University, 1280 Main Street West, Hamilton, \\ ON L8S 4L7, Canada; shakeria@mcmaster.ca (A.S.); yipdp@mcmaster.ca (D.Y.) \\ 2 School of Biomedical Engineering, McMaster University, 1280 Main Street West, Hamilton, ON L8S 4L8, \\ Canada; badvm@mcmaster.ca (M.B.); moetakes@mcmaster.ca (S.M.I.) \\ 3 Nanophyll Inc., 175 Longwood Rd South, Hamilton, ON L8P 0A1, Canada; mehdi@nanophyll.com \\ 4 Institute for Infectious Disease Research (IIDR), McMaster University, 1280 Main Street West, Hamilton, \\ ON L8S 4L8, Canada \\ * Correspondence: didar@mcmaster.ca
}

Received: 17 May 2018; Accepted: 8 June 2018; Published: 13 June 2018

\begin{abstract}
The high photocatalytic power of $\mathrm{TiO}_{2}$ nanoparticles has drawn great attention in environmental and medical applications. Coating surfaces with these particles enables us to benefit from self-cleaning properties and decomposition of pollutants. In this paper, two strategies have been introduced to coat ceramic tiles with $\mathrm{TiO}_{2}$ nanoparticles, and the self-cleaning effect of the surfaces on degradation of an organic dye under ultraviolent (UV) exposure is investigated. In the first approach, a simple one-step heat treatment method is introduced for coating, and different parameters of the heat treatment process are examined. In the second method, $\mathrm{TiO}_{2}$ nanoparticles are first aminosilanized using (3-Aminopropyl)triethoxysilane (APTES) treatment followed by their covalently attachment onto $\mathrm{CO}_{2}$ plasma treated ceramic tiles via $N$-(3-Dimethylaminopropyl)- $N^{\prime}$-ethylcarbodiimide hydrochloride (EDC) and $N$-Hydroxysuccinimide (NHS) chemistry. We monitor $\mathrm{TiO}_{2}$ nanoparticle sizes throughout the coating process using dynamic light scattering (DLS) and characterize developed surfaces using X-ray photoelectron spectroscopy (XPS). Moreover, hydrophilicity of the coated surfaces is quantified using a contact angle measurement. It is shown that applying a one-step heat treatment process with the optimum temperature of $200{ }^{\circ} \mathrm{C}$ for $5 \mathrm{~h}$ results in successful coating of nanoparticles and rapid degradation of dye in a short time. In the second strategy, the APTES treatment creates a stable covalent coating, while the photocatalytic capability of the particles is preserved. The results show that coated ceramic tiles are capable of fully degrading the added dyes under UV exposure in less than $24 \mathrm{~h}$.
\end{abstract}

Keywords: $\mathrm{TiO}_{2}$ nanoparticles; self-cleaning; photocatalyst; heat treatment; APTES treatment

\section{Introduction}

$\mathrm{TiO}_{2}$ is one of the most well-known photocatalysts, which has been widely used for photodegradation of organic compounds and decomposition of pollutants [1-3]. While $\mathrm{TiO}_{2}$ with the bulk bandgap of $\sim 3.2 \mathrm{eV}$ (in anatase phase) is transparent to visible light, it could be activated under ultraviolet (UV) light illumination and create photo-generated charge carriers $[4,5]$. The electrons, which are excited by UV absorption, bring about reduction of oxygen molecules in air and produce superoxide radicals $\left(\mathrm{O}_{2} \bullet^{-}\right)$. The superoxide radicals are further reduced to form hydrogen peroxide $\left(\mathrm{H}_{2} \mathrm{O}_{2}\right)$ and subsequently hydroxyl radicals $(\mathrm{OH} \bullet)$ [6-8]. On the other hand, oxidation of water molecules by electron holes at the surface of the UV excited $\mathrm{TiO}_{2}$ particles can also lead to the 
formation of hydroxyl radicals and hydrogen peroxide [7,9]. These reactive oxygen species can drive decomposition of organic pollutants and inactivation of micro-organisms, such as Escherichia coli cell [10-12].

In addition to the photochemical power, $\mathrm{TiO}_{2}$ has several other advantages, such as chemical stability, nontoxicity, hydrophilicity and cost, which make it a promising candidate for many industrial and environmental applications, including air purification, water purification, and creation of self-cleaning tiles or glasses used in constructions [9,13-15]. From a biomedical perspective, photoexcited $\mathrm{TiO}_{2}$ nanoparticles (NPs) have been utilized for cancer cell therapeutics [16,17], self-sterilizing of catheters [18] and antibacterial surfaces, as well as photocatalytic disinfection $[19,20]$.

So far, various physical and chemical approaches have been employed in order to coat $\mathrm{TiO}_{2}$ NPs onto different types of surfaces. One of the most commonly used coating methods is the sol-gel deposition technique, which enables a uniform thin $\mathrm{TiO}_{2}$ layer on different substrates [21-24]. Applying organic and inorganic binding agents capable of creating strong adhesion of $\mathrm{TiO}_{2}$ is the other widely used strategy to directly coat different substrates with pre-synthesized $\mathrm{TiO}_{2}$ particles [25]. Sopyan et al. have added $\mathrm{TiO}_{2}$ particles to a paint-like sol composed of fluoropolymer resin and an organotitanium coupling agent. The sol was coated onto a glass substrate and cured at $120^{\circ} \mathrm{C}$ [26]. Lin et al. have coated polyvinyl chloride (PVC) polymeric substrate with $\mathrm{TiO}_{2}$ particles via dip-coating the substrate into Tetrahydrofuran (THF)-PVC- $\mathrm{TiO}_{2}$ suspension [27]. In this method, THF solvent can melt the PVC, providing a strong physical attachment between $\mathrm{TiO}_{2}$ particles and the substrate. In another research carried out by $\mathrm{Pal}$ et al., $\mathrm{TiO}_{2}$ particles were combined with the inorganic binder of potassium silicate, which can create chemical bonds with substrates by a silicification process, and were then applied onto the fired bricks [28].

Silanization of inorganic surfaces with (3-Aminopropyl)triethoxysilane (APTES) is a widely known procedure to functionalize the surfaces with amino terminal groups, which could then be used to anchor different biomolecules (i.e., antibodies and proteins) via creating covalent peptide bonds [29-31]. The silanization process creates self-assembled monolayers (SAMs) of desired functional groups onto the surfaces and can be performed via chemical vapor deposition [32,33], liquid phase deposition (LPD) [34] and micro-contact printing [35-37]. APTES treatment has also been applied on $\mathrm{TiO}_{2}$ particles for various purposes, such as enhancement of proteins immobilization [38], preventing the UV photobleaching [39], and grafting with thermoresponsive polymers which enables $\mathrm{TiO}_{2}$ particles to have self-flocculation and temperature-controlled switching photocatalytic properties [40]. However, so far, this method has not been utilized to coat construction materials, such as ceramic tiles with $\mathrm{TiO}_{2}$ particles.

Heat treatment is also a determining factor in many $\mathrm{TiO}_{2}$ coating techniques. It is possible to precisely control the morphology, distribution, and size of the $\mathrm{NPs}$ in $\mathrm{TiO}_{2}$ coating via adjusting the heat treatment parameters such as temperature and time [41-43]. In addition, heat treatment method has a prominent role in doping $\mathrm{TiO}_{2}$ crystal structure with different dopants such as nitrogen and carbon for the sake of photocatalytic activity $[44,45]$.

In this paper, two different strategies were introduced to create a stable covalent coating of $\mathrm{TiO}_{2}$ NPs onto ceramic tiles to induce self-cleaning capability. In the first approach, a single heat treatment step was used to make a strong physical bond between the $\mathrm{TiO}_{2}$ particles and the ceramic tile. In the second procedure, we used the APTES treatment technique to functionalize $\mathrm{TiO}_{2}$ particles, and then the particles were covalently bonded to $\mathrm{CO}_{2}$ plasma treated ceramic tiles. In both approaches, we have shown that the photocatalytic power of particles was preserved, the coating was stable, and the surfaces were able to thoroughly degrade the dye that was used as an organic pollutant. 


\section{Materials and Methods}

\subsection{Materials}

$\mathrm{TiO}_{2}$ particles grade SSP-20 (Sakai Chemical Industry Co., Osaka, Japan) with a fully anatase crystal structure, a pink food dye (A Preema Quality Product, Ingredients: Sodium Chloride and E122 Carmosine), glazed ceramic tiles with the dimension of $\sim 3 \times 3 \mathrm{~cm}^{2}$ (The Home Depot, Hamilton, ON, Canada), triethylamine (Sigma-Aldrich, Oakville, ON, Canada), ammonium hydroxide (Sigma-Aldrich, Oakville, ON, Canada), APTES (Sigma Aldrich, Oakville, ON, Canada), toluene (Sigma-Aldrich, Oakville, ON, Canada), N-(3-Dimethylaminopropyl)-N'-ethylcarbodiimide hydrochloride (EDC) (Sigma-Aldrich, Oakville, ON, Canada), and N-Hydroxysuccinimide (NHS) (Sigma-Aldrich, Oakville, $\mathrm{ON}_{\text {, }}$ Canada) were used as received.

\subsection{Dye-Degradation Measurements}

Dye-degradation experiments were conducted using a custom-made UV chamber (Figure 1). We used a 10-watts Ultraviolet (UV) lamp (Ster-L-Ray, Preheat Germicidal Ultraviolet Lamps, Atlantic Ultraviolet Corporation, Hauppauge, NY, USA) with a total UV output of $2.7 \mathrm{~W}$, a length of $21 \mathrm{~cm}$, and a diameter of $\sim 1.5 \mathrm{~cm}$. The chamber dimensions were $26 \times 33 \times 25 \mathrm{~cm}^{3}$, and the distance from the lamp to the samples was around $3.5 \mathrm{~cm}$. The chamber was covered with an aluminum foil to enhance the reflection.

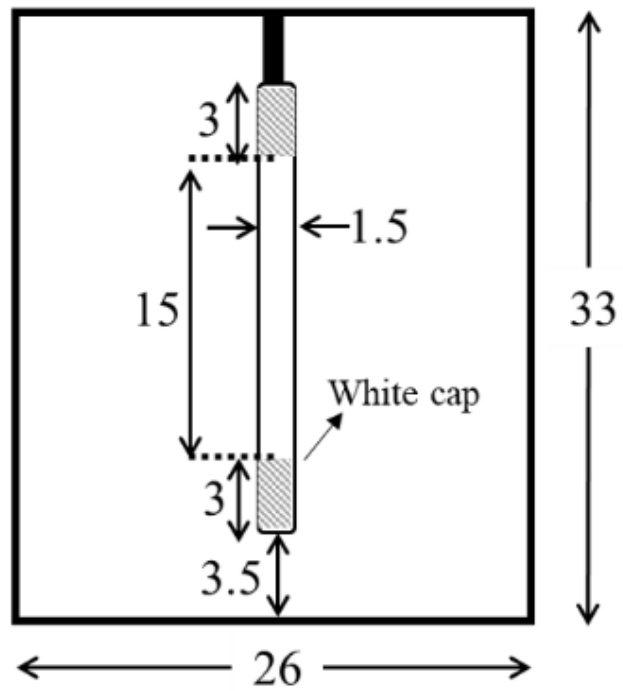

Figure 1. Schematic drawing of the custom-made UV chamber with a UV lamp at the center. All dimensions are in $\mathrm{cm}$.

\subsection{Dye-Degradation Measurement of $\mathrm{TiO}_{2}$ Nanoparticles}

The Ultraviolet-Visible (UV-VIS) spectrum of the dye was first measured to determine the optimal wavelength. This was done by using a $1.0 \mathrm{mg} / \mathrm{mL}$ concentration of the dye in deionized water and absorbances were read using a plate reader (Infinite M200 Pro, Tecan, Männedorf, Switzerland). The optimal wavelength was determined, based on results obtained using a range of excitation wavelengths. This wavelength was then used to produce a calibration curve to determine the concentration of the dye during the process of cleaning. The calibration graph was produced by measuring the absorbances for dye concentrations of $1,0.85,0.70,0.55,0.40,0.25$, and $0.1 \mathrm{mg} / \mathrm{mL}$, respectively. Then, $\mathrm{TiO}_{2} \mathrm{NPs}$ with a concentration of $1 \mathrm{mg} / \mathrm{mL}$ in deionized water were mixed with $1 \mathrm{mg} / \mathrm{mL}$ of the coloring dye. The suspension was then kept in the UV chamber while stirring to provide consistency with the reaction. A small sample was retrieved from the reaction at 5, 15, 30, 
60,180 , and $360 \mathrm{~min}$, and put into a microcentrifuge tube. The tube was then spun at $14,800 \mathrm{rpm}$ for $10 \mathrm{~min}$ to pellet the $\mathrm{TiO}_{2}$ NPs out of the suspension. Next, $100 \mu \mathrm{L}$ of the supernatant was gently pipetted from the microcentrifuge tube to the well plate. The well plate was then scanned using the plate reader, and the data obtained was graphed and interpreted.

\subsection{Coating $\mathrm{TiO}_{2}$ Nanoparticles Using Heat Treatment Technique}

Thirty microliter of $1 \mathrm{mg} / \mathrm{mL} \mathrm{TiO}_{2}$ NPs suspension was added onto the ceramic tiles' surfaces and spread to cover the whole surface using a simple pipetting system, and then left to dry at room temperature. The surfaces were then placed in a tube furnace or a vacuum oven for lower temperatures. The heat treatments were done in different durations of $2 \mathrm{~h}$ and $5 \mathrm{~h}$, and at different temperatures of $100,200,400,500,700$ and $900{ }^{\circ} \mathrm{C}$. The rate of the temperature gradient in all experiments was $5{ }^{\circ} \mathrm{C} / \mathrm{min}$. Following heat treatment, the surfaces were rinsed and wiped to remove any unattached particle (Figure 2a). Five microliter of $1 \mathrm{mg} / \mathrm{mL}$ of dye was added onto each surface and placed in the UV chamber to evaluate the amount of dye degradation in different time intervals.

(a)

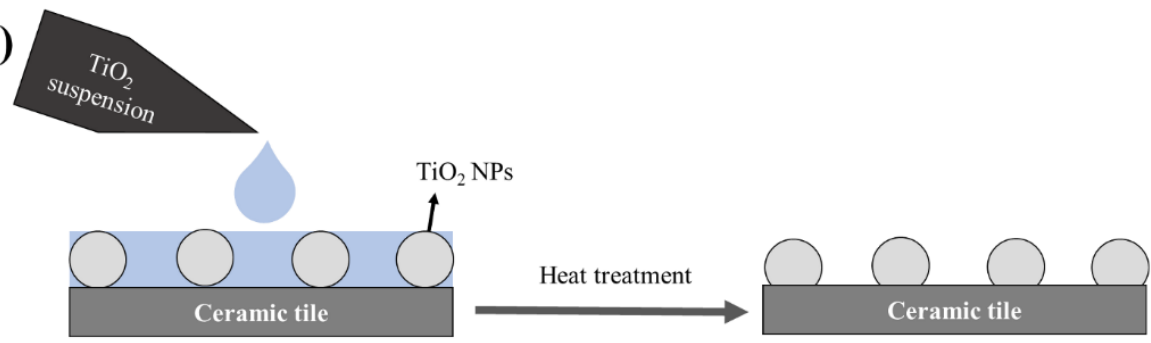

(b)

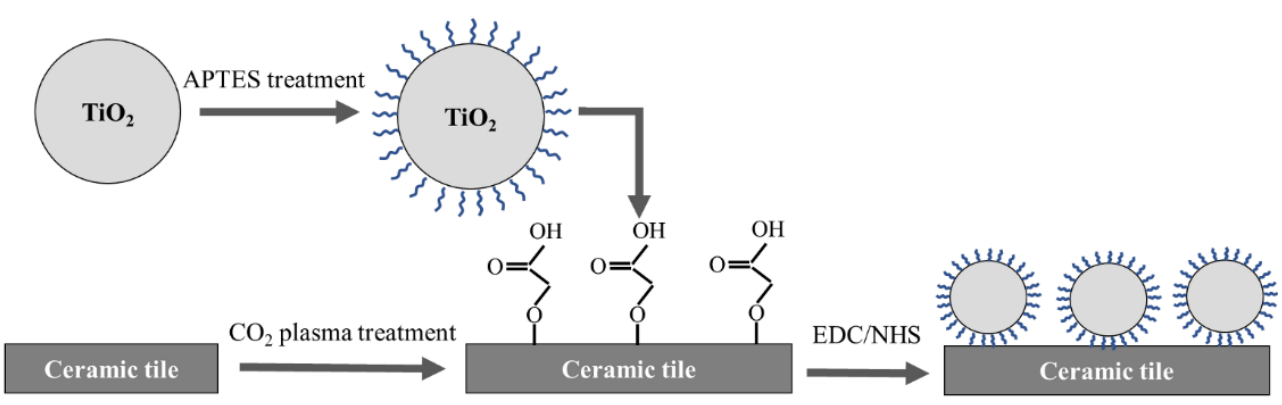

Figure 2. Schematic representation of (a) a heat treatment method and (b) an APTES treatment method for coating $\mathrm{TiO}_{2} \mathrm{NPs}$ on ceramic tiles.

\subsection{APTES Treatment Technique}

$\mathrm{TiO}_{2}$ NPs were homogenized with triethylamine (for improving the particle dispersion [46]) and ethanol at $60^{\circ} \mathrm{C}$. Further, ammonium hydroxide, deionized water (DI) water, and APTES ( 1\%) were added to the suspension and left to stir overnight. [40]. Ammonium hydroxide as a catalyst can increase the rate of APTES hydrolysis reactions [47]. Finally, the suspension was centrifuged at $4500 \mathrm{rpm}$ for $15 \mathrm{~min}$. The supernatant was discarded, and the pellet was mixed with ethanol. The washing step was repeated 3 times and the obtained powder was stored in $50 \mathrm{~mL}$ of toluene.

In order to coat ceramic tiles with the APTES treated particles, the cleaned surfaces were $\mathrm{CO}_{2}$ plasma treated (Harrick Plasma, Ithaca, NY, USA) to create carboxylic groups onto the surface. EDC-NHS chemistry (a molar ratio of EDC:NHS: 1:1) was used to activate the carboxylic groups on the surfaces. The solution was rinsed off the surface with DI water, and then the APTES treated $\mathrm{TiO}_{2}$ suspension was added to the surfaces and left for $2 \mathrm{~h}$. Finally, the surfaces were rinsed with DI water and dried at room temperature (Figure 2b). Five microliter of $1 \mathrm{mg} / \mathrm{mL}$ dye was added to the surfaces and left to dry. The surfaces were placed in the UV chamber and imaged at different time intervals. 


\subsection{Characterization Techniques}

High-resolution XPS was used to investigate the amount of carboxylic groups induced by $\mathrm{CO}_{2}$ plasma treatment of glass slides for different time durations. XPS measurements were carried out at binding energy between $\sim 280$ to $\sim 300(\mathrm{eV})$ to capture bond of $\mathrm{O}-\mathrm{C}=\mathrm{O}, \mathrm{C}=\mathrm{O}, \mathrm{C}-\mathrm{C}$, and $\mathrm{C}-\mathrm{O}$ as counts per second. The size distribution profile of the $\mathrm{TiO}_{2} \mathrm{NPs}$ in suspension was determined using the dynamic light scattering method (DLS, Beckman Coulter, Indianapolis, IN, USA). In DLS analysis, 10 acquisitions were performed for every experiment, and each acquisition was $15 \mathrm{~s}$ long. $\mathrm{All}_{\mathrm{TiO}} \mathrm{NPs}_{\mathrm{s}}$ were diluted in DI water with the concentration of $0.01 \mathrm{mg} / \mathrm{mL}$ and sonicated for $5 \mathrm{~min}$. For the APTES treated sample, we took $5 \mu \mathrm{L}$ of the suspension of NPs in toluene and diluted in DI water $(10 \mathrm{~mL})$ to achieve the desired concentration in order to exclude the effect of toluene in DLS measurements. Contact angles were measured by an optical contact angle (OCA 35) (Future Digital Scientific Corp., Garden City, NY, USA) using $5 \mu \mathrm{L}$ droplet of DI water. Fourier-transform infrared spectroscopy (FT-IR) (Bruker, Karlsruhe, Germany) was used to confirm the presence of the $\mathrm{TiO}_{2}$ coating on the ceramic tiles' surfaces after the washing steps as well as the effect of APTES treatment on the $\mathrm{TiO}_{2} \mathrm{NPs}$. FT-IR was conducted on different samples and different spots on the surfaces for each experiment. ImageJ was utilized to quantify the photos achieved from the dye-degradation results. For better comparison, the graphs were normalized, so that all the graphs started at the same point. Atomic force microscopy (AFM) (BioScope Catalyst, Bruker, Milton, ON, Canada) was performed to analyze surface topography and roughness within the scan size of $1 \times 1 \mu \mathrm{m}^{2}$. A ScanAsyst mode was utilized in the measurements using a probe with the spring constant of $0.4 \mathrm{~N} / \mathrm{m}$.

\section{Results and Discussion}

\section{1. $\mathrm{TiO}_{2} \mathrm{NPs}$ Size Measurements}

Figure 3 demonstrates the average particle sizes of untreated $\mathrm{TiO}_{2}$ NPs and APTES treated $\mathrm{TiO}_{2}$ NPs versus the particles population percentage. As is shown, the average radius of the untreated NPs was mostly distributed in two different sizes of $123 \mathrm{~nm}$ (24.3\% of particle number) and $449 \mathrm{~nm}$ (75.7\% of particle number). The existence of the larger particle sizes could be due to the NPs agglomeration even after the sonication. In Figure 3b, there were also two main particle size distributions associated with the APTES treated NPS. At the first peak, the average radius was almost the same as the untreated NPS. However, the number of NPs with that radius decreased, compared to the untreated NPs. Moreover, APTES treatment caused the second distribution to go up in terms of average radius as well as population density of the NPs. Consequently, APTES treatment of the particles caused a slight increase in the particles agglomeration, although this was not significant. 

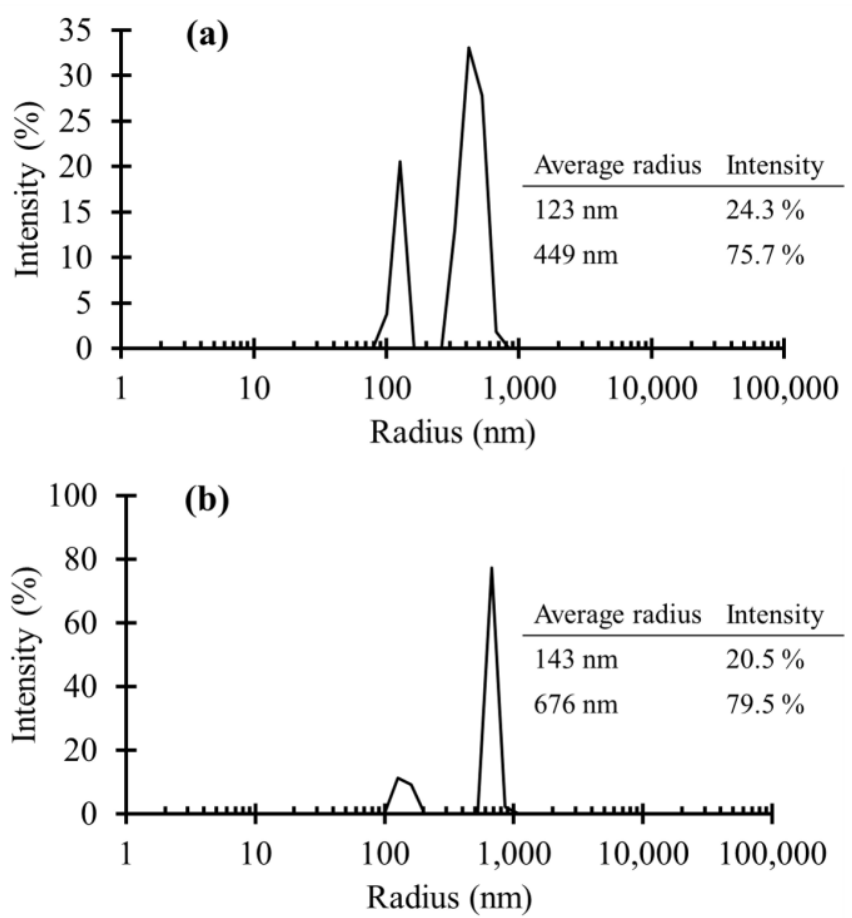

Figure 3. DLS results of the (a) untreated $\mathrm{TiO}_{2} \mathrm{NPs}$ and (b) APTES treated $\mathrm{TiO}_{2} \mathrm{NPs}$. The vertical axes indicate the particle number percentages. The insect tables show the average radius of the NPs and related particle number intensities.

\subsection{XPS Measurement of the $\mathrm{CO}_{2}$ Plasma Treated Ceramic Tiles}

The second approach that we employed to covalently bind $\mathrm{TiO}_{2} \mathrm{NPs}$ to the surface of ceramic tiles was aminosilanization of $\mathrm{TiO}_{2} \mathrm{NPs}$ and $\mathrm{CO}_{2}$ plasma treatment of ceramic tiles. APTES treatment of $\mathrm{TiO}_{2} \mathrm{NPs}$ formed a monolayer of hydrolyzed and condensed APTES molecules on the surface providing free terminal $\mathrm{NH}_{2}$ groups. Schematic presentation of this functionalization process is shown in Figure $2 \mathrm{~b}$. On the other hand, $\mathrm{CO}_{2}$ plasma treatment of ceramic tiles can produce carboxylic groups $(\mathrm{COOH})$ on the surface, which can subsequently be activated using EDC/NHS chemistry. The functional carboxylic groups can go through a chemical reaction with amino groups of the APTES treated particles and form covalent peptide bonds. Consequently, we would be able to covalently bind the $\mathrm{TiO}_{2}$ particles to the ceramic tiles.

To investigate the carboxylic group formation on the surface, a high-resolution XPS test was performed. Figure 4 a depicts the XPS results of an untreated sample. XPS graphs of $\mathrm{CO}_{2}$ plasma treated samples for different time periods are shown in Figure $4 \mathrm{~b}-\mathrm{d}$. The peaks at binding energies around $288.66(\mathrm{eV}), 286.02(\mathrm{eV})$, and $284.8(\mathrm{eV})$ were assigned to $\mathrm{O}-\mathrm{C}=\mathrm{O}, \mathrm{C}=\mathrm{O}$, and $\mathrm{C}-\mathrm{C}$ as well as $\mathrm{C}-\mathrm{O}$, respectively [48]. Figure 4e demonstrates the variation in the amount of $\mathrm{O}-\mathrm{C}=\mathrm{O}$ groups by increasing the $\mathrm{CO}_{2}$ plasma treatment time. It could be seen that after 2 min of plasma treatment, the $\mathrm{O}-\mathrm{C}=\mathrm{O}$ band area in XPS patterns has risen from $6.46 \%$ to $16.58 \%$, indicating the well formation of carboxylic groups via the $\mathrm{CO}_{2}$ plasma treatment. Increasing the plasma treatment time more than $2 \mathrm{~min}$ did not significantly change the $\mathrm{O}-\mathrm{C}=\mathrm{O} \%$ area. 

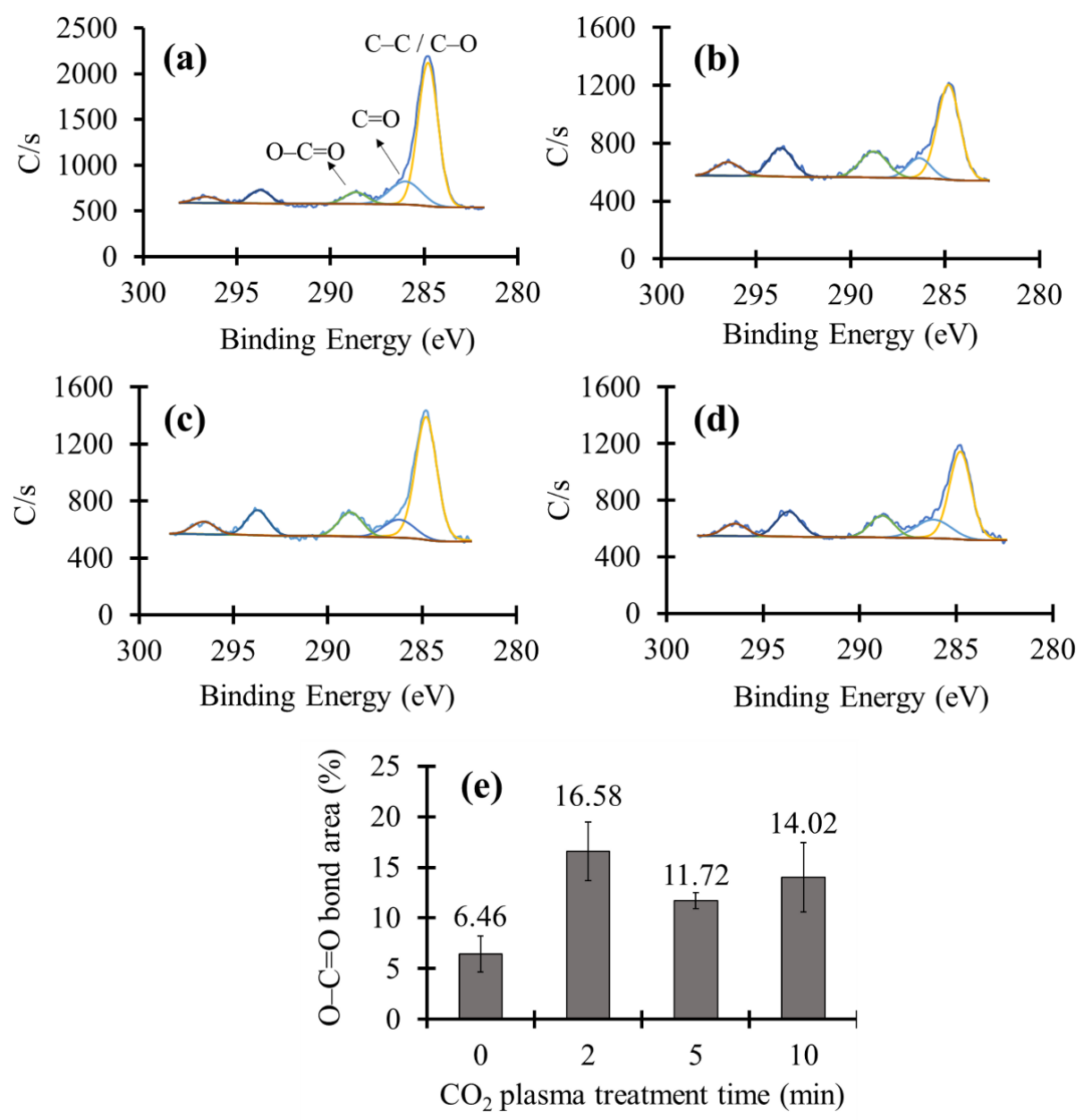

Figure 4. High-resolution XPS plots of $\mathrm{CO}_{2}$ plasma treated glass surfaces for (a) $0 \mathrm{~min}$; (b) $2 \mathrm{~min}$; (c) $5 \mathrm{~min}$; and (d) $10 \mathrm{~min}$; (e) Variation of the amount of $\mathrm{O}-\mathrm{C}=\mathrm{O}$ bonds versus plasma treatment time.

\subsection{FT-IR Studies of the $\mathrm{TiO}_{2}$ Coated Tiles}

FT-IR spectra of plain ceramic tiles, as well as the tiles coated with $\mathrm{TiO}_{2} \mathrm{NPs}$ using heat treatment and APTES treatment methods, are plotted in Figure 5. In FT-IR measurements, the surface of a plain ceramic tile was considered to be the background, and all other spectra were normalized based on that. As a control, we applied untreated $\mathrm{TiO}_{2} \mathrm{NPs}$ on ceramic tiles and then performed the regular washing steps. It can be seen that the obtained spectrum was a flat line similar to the background, indicating a complete removal of the $\mathrm{TiO}_{2} \mathrm{NPs}$ during the washing process. Nevertheless, the spectra of the $\mathrm{TiO}_{2}$ coated ceramic tiles using the heat treatment protocol had a number of peaks in the absorption band between 400 to $1200 \mathrm{~cm}^{-1}$, mainly at $400 \mathrm{~cm}^{-1}, 790 \mathrm{~cm}^{-1}$, and $900 \mathrm{~cm}^{-1}$. This absorption band could be ascribed to the Ti-O stretching and Ti-O-Ti bridging stretching modes [49-53]. Thus, the results demonstrated the presence of $\mathrm{TiO}_{2} \mathrm{NPs}$ onto the surface of the tiles after performing the washing steps. This is due to the strong adhesion of $\mathrm{TiO}_{2} \mathrm{NPs}_{\text {to }}$ the surface induced via the heat treatment at $200{ }^{\circ} \mathrm{C}$ for $5 \mathrm{~h}$ (the optimum heat treatment condition based on the dye-degradation results in Figure 10). Figure 5 also depicts the same FT-IR spectra for the APTES treated NPs bonded to the plasma treated ceramic tiles. Moreover, the transmittance percentages of the peaks were almost the same as those of the heat-treated samples, which roughly illustrated the equal mass of $\mathrm{TiO}_{2}$ coating. The results confirmed the stable bond formation between $\mathrm{TiO}_{2} \mathrm{NPs}$ and the substrate that retained the NPs onto the surface during the washing steps. 


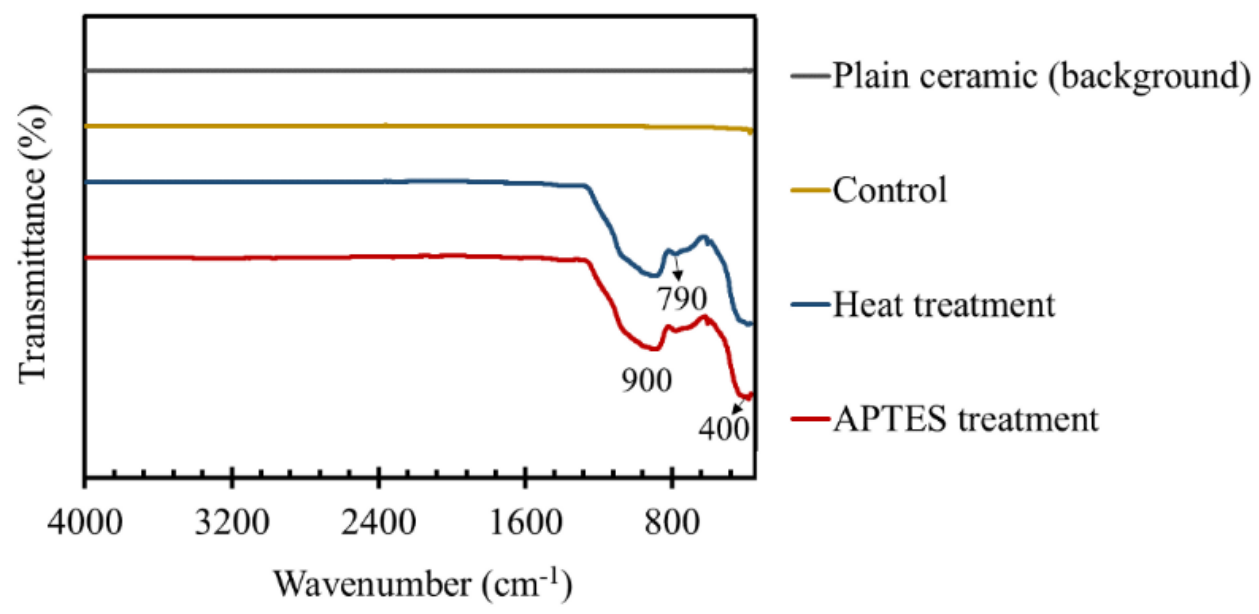

Figure 5. FT-IR spectra of a plain ceramic tile indicated as the background, a control ceramic tile in which untreated particles were applied to the substrate and then the washing steps were conducted, a $\mathrm{TiO}_{2}$ coated ceramic tile using the heat treatment method at $200{ }^{\circ} \mathrm{C}$ for $5 \mathrm{~h}$, and a $\mathrm{TiO}_{2}$ coated ceramic tile using an APTES treatment protocol.

In Figure 6, the FT-IR spectra of APTES treated $\mathrm{TiO}_{2}$ NPs and untreated NPs were compared at the wavenumber between 2400 to $4000 \mathrm{~cm}^{-1}$ to confirm the efficacy of APTES functionalization. There are two main peaks at $\sim 2900$ and $\sim 3300$ in the transmittance spectrum of untreated $\mathrm{TiO}_{2} \mathrm{NPs}_{\text {, which }}$ indicate the presence of hydroxyl groups on the surface of the NPs. The first peak could be associated with both symmetric and asymmetric $\mathrm{CH}_{2}$ stretching vibrations in $-\mathrm{CH}_{2}-\mathrm{OH}$ compound [54], and the second peak was attributed to hydroxyl group symmetric and asymmetric stretching vibrations in Ti-OH compounds [49]. The hydroxyl groups can be formed due to the chemical and physical adsorptions of atmosphere moisture on the surface of NPs [49,55]. As shown in Figure 6, for the APTES treated particles, the peaks related to hydroxyl groups almost disappeared, and a broad peak between 2800 to $3600 \mathrm{~cm}^{-1}$ was formed in the spectrum of APTES treated NPs instead. This is because of the hydrolysis and condensation reactions of the silane head groups in APTES molecules and anchoring to the hydroxyl groups of the NPs surfaces to form oxane (Si-O-M) bonds [56]. The broad peak could be caused by $\mathrm{OH}$ stretching in silanol $(\mathrm{Si}-\mathrm{OH})$ groups $\left(3200-3700 \mathrm{~cm}^{-1}\right)$ formed via hydrolysis of APTES, primary amine $\left(3160-3450 \mathrm{~cm}^{-1}\right)$, as well as alkane $\mathrm{C}-\mathrm{H}$ stretching vibrations in $-\mathrm{CH}_{3}$ and $-\mathrm{CH}_{2}-$ (2840-2975 $\mathrm{cm}^{-1}$ ) due to the presence of APTES molecules [54].

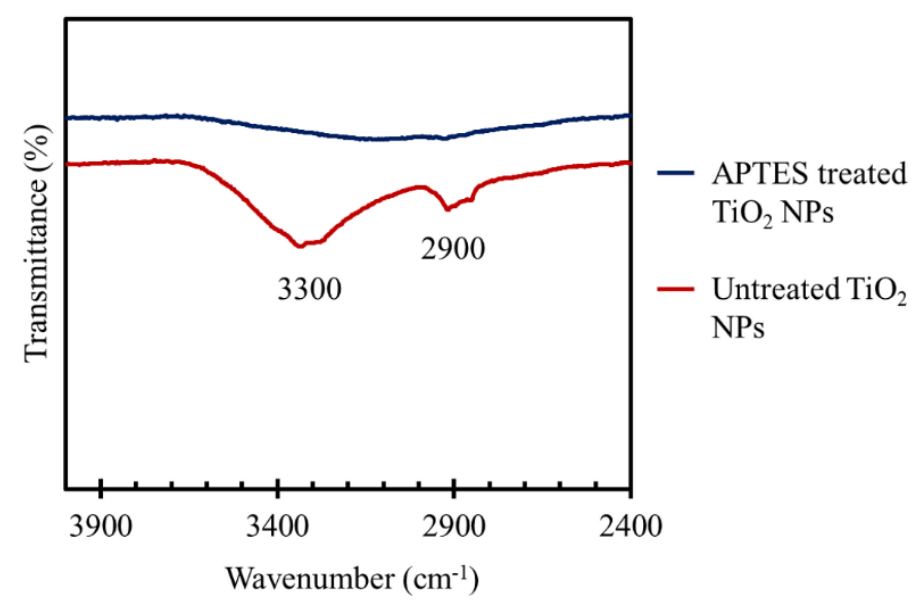

Figure 6. FT-IR spectra of the APTES treated $\mathrm{TiO}_{2}$ NPs compared to untreated NPs at the wavenumber between 2400 to $4000 \mathrm{~cm}^{-1}$. 


\subsection{Hydrophilicity and Surface Topography of the $\mathrm{TiO}_{2}$ Coated Tiles}

The results of the contact angle measurement are shown in Figure 7. The contact angle of plain ceramic tiles was about $25.8 \pm 4.0^{\circ}$ indicating the hydrophilic behavior of the surfaces. By performing heat treatment, although surfaces remained hydrophilic, the contact angle rose to $77.8 \pm 3.2^{\circ}$. This unexpected increase in contact angle could be due to the surface roughness generated by partial diffusion of $\mathrm{TiO}_{2}$ NPs into the surface, which can compensate for the inherent hydrophilicity of $\mathrm{TiO}_{2}$ [57]. The APTES treatment method, on the other hand, resulted in more hydrophilic $\mathrm{TiO}_{2}$ coated surfaces with the contact angle of less than $5^{\circ}$. A possible explanation for that is $\mathrm{CO}_{2}$ plasma treatment step during the APTES treatment protocol, which can greatly increase hydrophilicity as well as the APTES coating on the surface of the NPs [58].

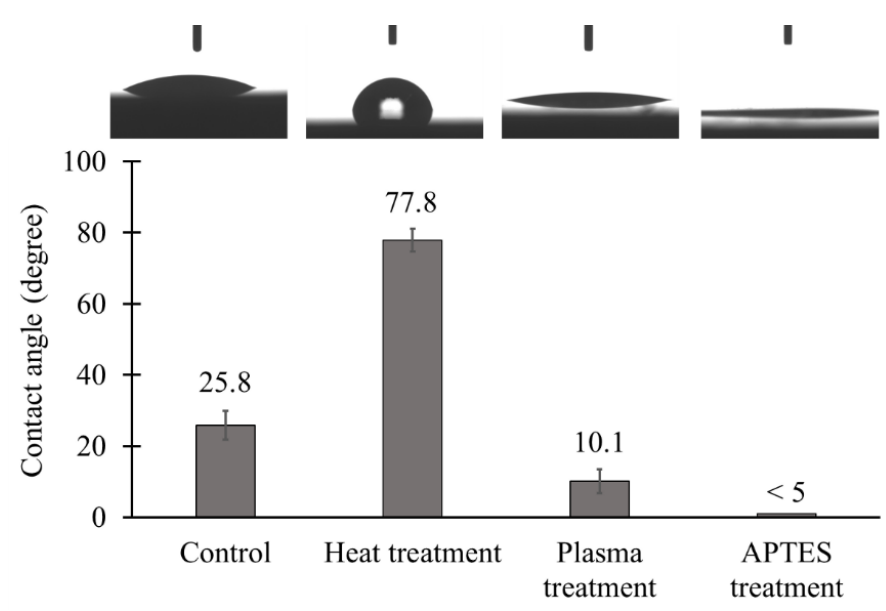

Figure 7. Contact angles of plain ceramic tiles (control), $\mathrm{TiO}_{2}$ coated ceramic tiles via the heat treatment method at $200{ }^{\circ} \mathrm{C}$ for $5 \mathrm{~h}, \mathrm{CO}_{2}$ plasma treated ceramic tiles, and $\mathrm{TiO}_{2}$ coated ceramic tiles via the APTES treatment method $(n=3)$.

AFM images of the $\mathrm{TiO}_{2}$ coated ceramic tiles are illustrated in Figure 8. The density of the NPs in the heat-treated sample (Figure 8a) was higher, compared to the sample coated with the APTES treatment protocol (Figure $8 \mathrm{~b}$ ). Furthermore, the root-mean-square (RMS) surface roughness of the ceramic tile increased from $0.676 \mathrm{~nm}$ for a plain ceramic to $1.26 \mathrm{~nm}$ for $\mathrm{TiO}_{2}$ coated ceramic using the APTES treatment method. The RMS parameter of the $\mathrm{TiO}_{2}$ coated ceramic tiles with the heat treatment process was $1.82 \mathrm{~nm}$, which was more than that for tiles with the APTES treatment protocol due to the higher number of NPs on the surface.
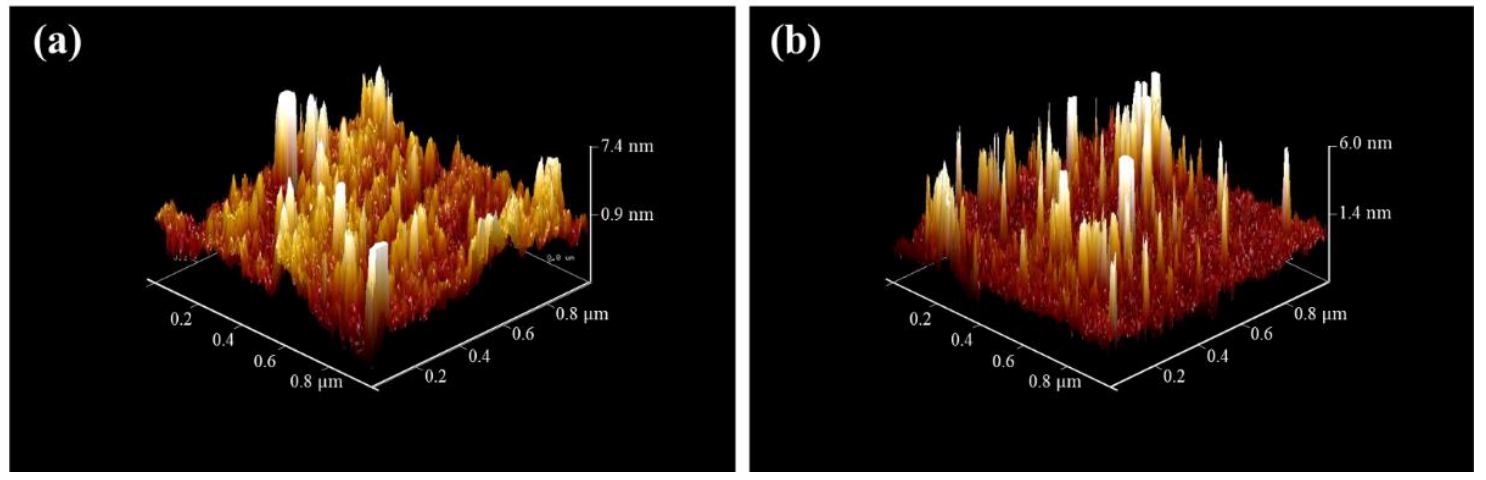

Figure 8. 3D AFM images of ceramic tile surfaces coated with $\mathrm{TiO}_{2} \mathrm{NPs}$ using (a) heat treatment at $200{ }^{\circ} \mathrm{C}$ for $5 \mathrm{~h}$ and $(\mathbf{b})$ the APTES treatment method. 


\subsection{Dye Degradation of $\mathrm{TiO}_{2}$ NPs in Suspension}

In order to achieve the proper wavelength for reading the absorbances of the dye with a plate reader, the full absorbance spectra of $1 \mathrm{mg} / \mathrm{mL}$ concentration of the dye diluted in deionized water was measured. As shown in Figure 9a, the sharp peak at the wavelength of $512 \mathrm{~nm}$, which can be easily distinguished, was used as a reference wavelength for the next absorbance measurements. The calibration curve for dye absorbance as a function of concentration at the wavelength of $512 \mathrm{~nm}$ is illustrated in Figure 9b. The obtained scatter diagram has a linear trend line. To measure the photocatalytic power of $\mathrm{TiO}_{2} \mathrm{NPs}$, the particles were added to the $1 \mathrm{mg} / \mathrm{mL}$ dye solution and were kept in the UV light, under a constant stirring condition. The amount of dye-degradation induced by $\mathrm{TiO}_{2}$ photocatalyst could be calculated based on Figure $9 \mathrm{~b}$. The dye concentration results versus UV exposure time are shown in Figure 9c. As is shown, a considerable reduction in the dye concentration was achieved after $15 \mathrm{~min}$ where almost half of the dye was degraded, and the concentration reached $0.55 \mathrm{mg} / \mathrm{mL}$. Afterwards, the rate of dye degradation became slower and after 1 day of UV irradiation, the dye concentration decreased down to $0.26 \mathrm{mg} / \mathrm{mL}$. Thus, the $\mathrm{TiO}_{2}$ nanoparticles possessed a considerable photocatalytic power in suspension. The reason why the expected exponential decay to zero was not observed in our sample could be attributed to the absorption of the partial degradation products on the photocatalyst surface and/or the $\mathrm{pH}$ variation of the suspension leading to deterioration in the dye-degradation process.
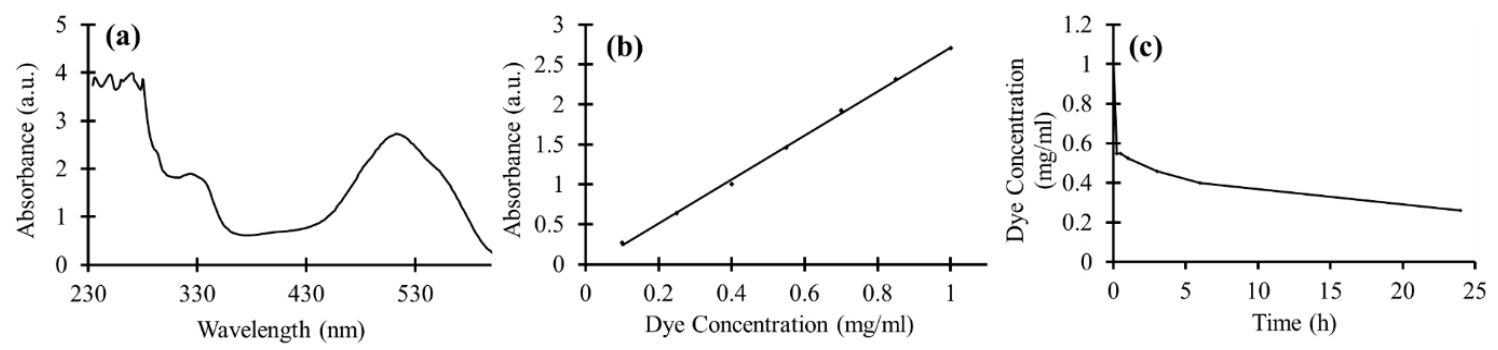

Figure 9. (a) UV-VIS spectra of $1 \mathrm{mg} / \mathrm{mL}$ concentration of the dye; (b) Absorbance curve as a function of dye concentration at the wavelength of $512 \mathrm{~nm}$; (c) Dye concentration mixed with $\mathrm{TiO}_{2} \mathrm{NPs}$ suspension as a function of UV exposure time.

\subsection{Dye Degradation on $\mathrm{TiO}_{2}$ Coated Tiles Produced Using Heat Treatment}

Figure 10 demonstrates the dye-degradation properties of ceramic tiles coated with $\mathrm{TiO}_{2}$ nanoparticles using the heat treatment approach at different temperatures and incubation time ( 1 and 5 h). Control ceramic tiles were incubated with a suspension of $\mathrm{TiO}_{2} \mathrm{NPs}$ with the same incubation time, but no heat treatment was involved (labeled by "no heat treatment" in Figure 10). Following the washing step, all $\mathrm{TiO}_{2} \mathrm{NPs}$ were detached from the surface of control tiles and therefore, no dye degradation was observed. Moreover, when the samples were heat treated for $1 \mathrm{~h}$ (Figure 10a), no dye-degradation properties were recorded at any heat treatment temperatures. One major problem with high temperatures of $700{ }^{\circ} \mathrm{C}$ and $900{ }^{\circ} \mathrm{C}$ is that since the temperatures were above the phase transition temperature of $\mathrm{TiO}_{2}$ from anatase to rutile [59-62], the formed rutile phase could have deteriorated the photocatalytic activity of the $\mathrm{TiO}_{2}$ particles even if the particles were successfully attached to the ceramic tiles. It has been proved that $\mathrm{TiO}_{2}$ exhibits a higher photocatalytic activity in anatase phase compared to fully rutile phase, which may be due to larger band gap in anatase compared to rutile $\mathrm{TiO}_{2}$ [4]. Thus, the optimal temperature for heat treatment should not change the structure of $\mathrm{TiO}_{2}$. According to the composite phase diagram of $\mathrm{TiO}_{2}$, the anatase-rutile phase transition takes place at around $600{ }^{\circ} \mathrm{C}$ at atmospheric pressure [59]. 


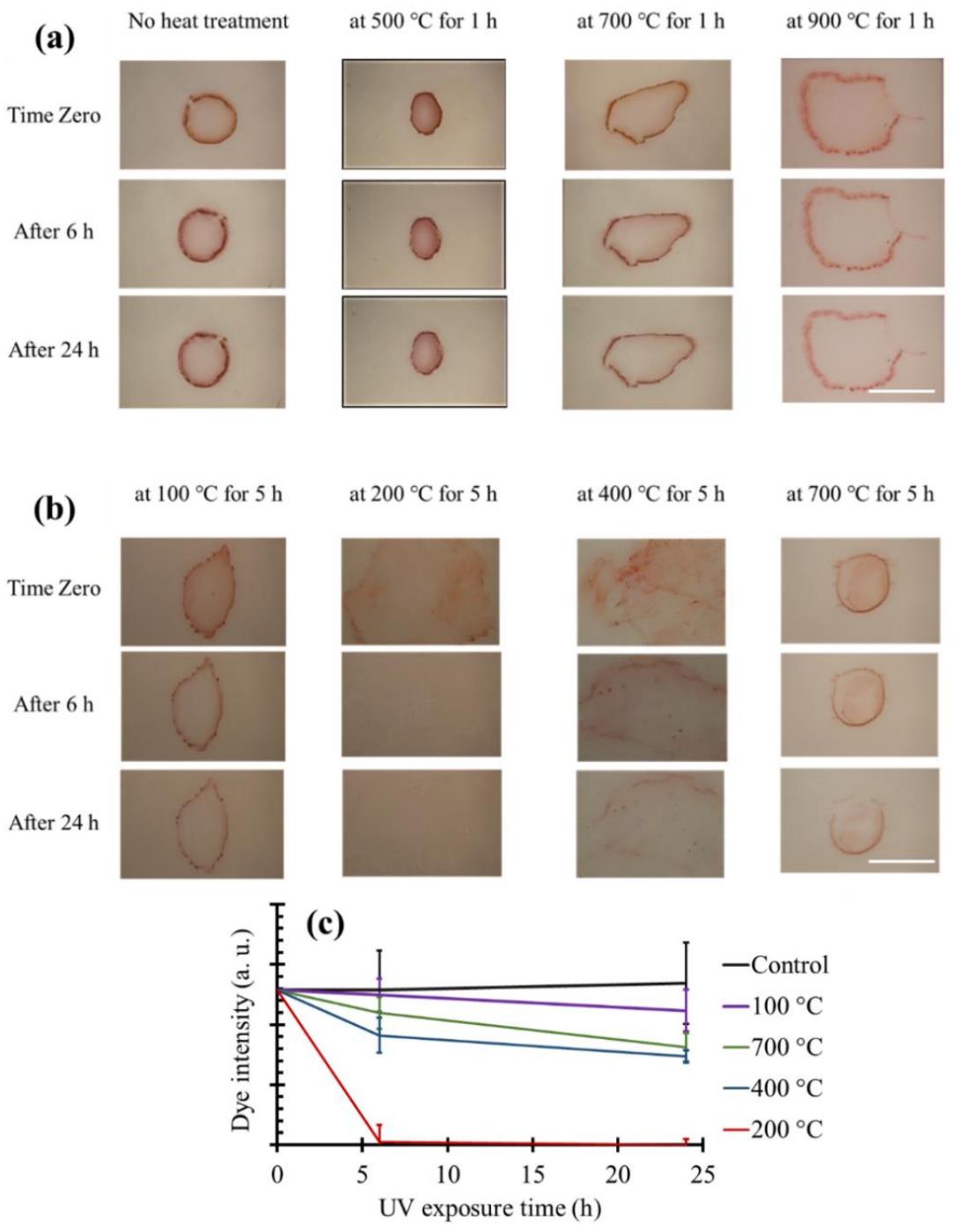

Figure 10. Dye-degradation results of the heat-treated ceramic tiles under UV exposure. Heat treatment was performed at different temperatures for $1 \mathrm{~h} \mathrm{(a)} \mathrm{and} 5 \mathrm{~h} \mathrm{(b)}$. Scale bars are $1 \mathrm{~cm}$. (c) Quantification of the dye degradation on the heat-treated samples for $5 \mathrm{~h}$ at different temperatures and the control sample without any heat treatment.

Therefore, we increased the heat treatment duration from $1 \mathrm{~h}$ to $5 \mathrm{~h}$ to investigate the effect of heat treatment time on the coating process, specially the possibility of successful and functional coating at lower temperatures. Figure 10b exhibits the dye-degradation trend for the ceramic tile samples, which were heat treated at varying temperatures for $5 \mathrm{~h}$. In Figure 10c, the results were also quantified for better comparison. The samples that were heat treated at $400{ }^{\circ} \mathrm{C}$ degraded the dye at a lower rate than heat treatment at $200{ }^{\circ} \mathrm{C}$, although both temperatures were below the anatase-rutile phase transition temperature. This can be caused by slightly more agglomeration of the $\mathrm{TiO}_{2} \mathrm{NPs}$ at $400{ }^{\circ} \mathrm{C}$ in comparison to $200{ }^{\circ} \mathrm{C}$, leading to a small increase in the average particle size and a reduction in the overall surface area of the particles, thereby diminishing the photocatalytic power. The other possible explanation could be attributed to the higher diffusion of NPs inside the glossy surface of the ceramic tiles at $400{ }^{\circ} \mathrm{C}$. Therefore, the smaller area of the particles would get in touch with the dye, causing a decrease in the dye-degradation rate. Performing the heat treatment at a more cost-effective temperature of $200{ }^{\circ} \mathrm{C}$ caused the dye to be fully degraded after $6 \mathrm{~h}$. Nevertheless, $100{ }^{\circ} \mathrm{C}$ heat treatment for $5 \mathrm{~h}$ appeared to be not enough for the $\mathrm{TiO}_{2}$ particles to be completely attached to the 
surface of ceramic tiles, thereby resulting in less dye degradation under UV exposure. Therefore, a $5 \mathrm{~h}$ heat treatment at $200{ }^{\circ} \mathrm{C}$ provided the best dye-degradation properties for the ceramic tiles.

\subsection{Dye Degradation on $\mathrm{TiO}_{2}$ Coated Tiles Produced Using Aminosilanization}

Figure 11a illustrates the dye-degradation results of the ceramic tiles coated with the APTES treatment method. Quantifications of the obtained results are plotted in Figure 11b. We applied untreated $\mathrm{TiO}_{2}$ particles onto the ceramic tiles as control samples. Most of the particles were removed from the surface during the washing process, and the dye was not degraded after 1 day in control samples. However, when APTES treated particles were used, the dye was almost invisible after 24 $h$, demonstrating excellent effectivity of the APTES treatment process for coating ceramic tiles with $\mathrm{TiO}_{2} \mathrm{NPs}$. In comparison to the heat treatment at $200{ }^{\circ} \mathrm{C}$ for $5 \mathrm{~h}$, coating the surfaces via the APTES treatment resulted in a lower rate of dye degradation due to two main reasons: a smaller number of particles on the surface which was confirmed with AFM test, and covering the particles via a silane coupling agent which can reduce the photoactivity of the particles [63]. Nevertheless, using the APTES treatment protocol has two important advantages. First, the method for functionalization using APTES is much simpler and does not require high temperatures compared to the heat treatment. Second, since this technique creates covalent bonds between $\mathrm{TiO}_{2} \mathrm{NPs}$ and surfaces, the durability of the coating would be higher in the long term.

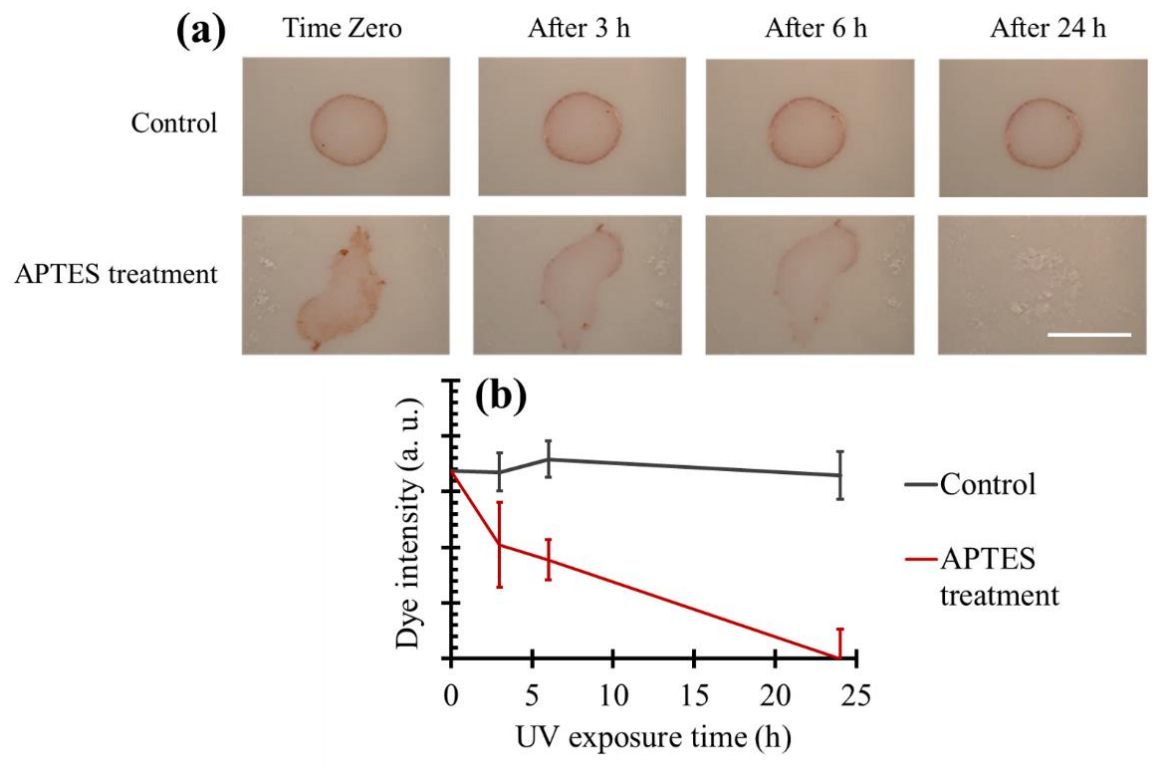

Figure 11. (a) Dye-degradation results of the ceramic tiles coated with $\mathrm{TiO}_{2}$ particles using the APTES treatment technique. Scale bar is $1 \mathrm{~cm}$. (b) Quantification of the dye-degradation images.

\section{Conclusions}

The photocatalytic power of $\mathrm{TiO}_{2}$ NPs measured inside the suspension showed a proper dye-degradation effect under UV exposure. We introduced two strategies to coat ceramic tiles with the $\mathrm{TiO}_{2}$ NPs. Both protocols led to transparent $\mathrm{TiO}_{2}$ coating on ceramic tiles without any adverse effect on the tile's physical appearance. In the heat treatment approach, it was shown that applying a simple one-step heat treatment with the optimum temperature of $200^{\circ} \mathrm{C}$ for $5 \mathrm{~h}$ resulted in rapid degradation of dye in a short time. In the second strategy, the APTES treatment method was employed to covalently bond the $\mathrm{TiO}_{2}$ particles to the $\mathrm{CO}_{2}$ treated ceramic tiles, while the photocatalytic power of the particles was preserved. The success of the covalent bonding protocol suggests a possible longer duration of the coating in harsh environments. In future, we will focus on enhancement of the self-cleaning behavior, as well as studying the durability of the coating by performing proper weathering tests. 
Author Contributions: T.F.D. conceived the research and supervised the experiments. A.S. performed the experiments, data validation, data visualization, and analysis with help from D.Y. A.S. wrote the manuscript with input from T.F.D. and M.S. M.B. conducted the FT-IR tests. S.M.I. performed the AFM analyses. All authors have read, commented and approved the final version of the paper.

Funding: This project was supported by an ENGAGE-OCE-VIPI grant from the Natural Science and Engineering Research Council of Canada (NSERC, Ontario Centers of Excellence (OCE) and Nanophyll Inc.

Conflicts of Interest: M.S. holds equity in Nanophyll Inc.

\section{References}

1. Dong, H.; Zeng, G.; Tang, L.; Fan, C.; Zhang, C.; He, X.; He, Y. An overview on limitations of TiO $\mathrm{T}_{2}$-based particles for photocatalytic degradation of organic pollutants and the corresponding countermeasures. Water Res. 2015, 79, 128-146. [CrossRef] [PubMed]

2. Weon, S.; Kim, J.; Choi, W. Dual-components modified $\mathrm{TiO}_{2}$ with $\mathrm{Pt}$ and fluoride as deactivation-resistant photocatalyst for the degradation of volatile organic compound. Appl. Catal. B Environ. 2018, 220, 1-8. [CrossRef]

3. Li, S.; Ishikawa, S.; Huang, C.; Zhang, W.; Tanizaki, T.; Higuchi, T.; Haraga, H. Production of active intermediates and decomposition behaviors of organic compounds in the ultraviolet ray/supersonic wave reactions with $\mathrm{TiO}_{2}$ photocatalyst. Sustain. Environ. Res. 2015, 25, 67-72.

4. Luttrell, T.; Halpegamage, S.; Tao, J.; Kramer, A.; Sutter, E.; Batzill, M. Why is anatase a better photocatalyst than rutile? Model studies on epitaxial $\mathrm{TiO}_{2}$ films. Sci. Rep. 2015, 4, 4043. [CrossRef] [PubMed]

5. Hashimoto, K.; Irie, H.; Fujishima, A. $\mathrm{TiO}_{2}$ photocatalysis: A historical overview and future prospects. Jpn. J. Appl. Phys. 2005, 44, 8269-8285. [CrossRef]

6. Nosaka, Y.; Nosaka, A.Y. Identification and roles of the active species generated on various photocatalysts. In Photocatalysis and Water Purification; Wiley-VCH Verlag GmbH \& Co. KGaA: Weinheim, Germany, 2013.

7. Fujishima, A.; Zhang, X.; Tryk, D.A. $\mathrm{TiO}_{2}$ photocatalysis and related surface phenomena. Surf. Sci. Rep. 2008, 63, 515-582. [CrossRef]

8. Fujishima, A.; Rao, T.N.; Tryk, D.A. Titanium dioxide photocatalysis. J. Photochem. Photobiol. C Photochem. Rev. 2000,1,1-21. [CrossRef]

9. Nakata, K.; Fujishima, A. $\mathrm{TiO}_{2}$ photocatalysis: Design and applications. J. Photochem. Photobiol. C Photochem. Rev. 2012, 13, 169-189. [CrossRef]

10. Marugán, J.; van Grieken, R.; Pablos, C.; Satuf, M.L.; Cassano, A.E.; Alfano, O.M. Photocatalytic inactivation of escherichia coli aqueous suspensions in a fixed-bed reactor. Catal. Today 2015, 252, 143-149. [CrossRef]

11. Liu, H.-L.; Yang, T.C.-K. Photocatalytic inactivation of escherichia coli and lactobacillus helveticus by $\mathrm{ZnO}$ and $\mathrm{TiO}_{2}$ activated with ultraviolet light. Process Biochem. 2003, 39, 475-481. [CrossRef]

12. Padervand, M.; Vossoughi, M.; Yousefi, H.; Salari, H.; Gholami, M.R. An experimental and theoretical study on the structure and photoactivity of $\mathrm{XFe}_{2} \mathrm{O}_{4}(\mathrm{X}=\mathrm{Mn}, \mathrm{Fe}, \mathrm{Ni}, \mathrm{Co}$, and $\mathrm{Zn})$ structures. Russ. J. Phys. Chem. A 2014, 88, 2451-2461. [CrossRef]

13. Banerjee, S.; Dionysiou, D.D.; Pillai, S.C. Self-cleaning applications of $\mathrm{TiO}_{2}$ by photo-induced hydrophilicity and photocatalysis. Appl. Catal. B Environ. 2015, 176-177, 396-428. [CrossRef]

14. Klein, M.; Grabowska, E.; Zaleska, A. Noble metal modified $\mathrm{TiO}_{2}$ for photocatalytic air purification. Physicochem. Probl. Miner. Process. 2015, 51, 49-57.

15. Song, J.; Wang, X.; Yan, J.; Yu, J.; Sun, G.; Ding, B. Soft Zr-doped $\mathrm{TiO}_{2}$ nanofibrous membranes with enhanced photocatalytic activity for water purification. Sci. Rep. 2017, 7, 1636. [CrossRef] [PubMed]

16. Imani, R.; Dillert, R.; Bahnemann, D.W.; Pazoki, M.; Apih, T.; Kononenko, V.; Repar, N.; Kralj-Iglič, V.; Boschloo, G.; Drobne, D.; et al. Multifunctional gadolinium-doped mesoporous $\mathrm{TiO}_{2}$ nanobeads: Photoluminescence, enhanced spin relaxation, and reactive oxygen species photogeneration, beneficial for cancer diagnosis and treatment. Small 2017, 13, 1-11. [CrossRef] [PubMed]

17. Seo, J.W.; Chung, H.; Kim, M.Y.; Lee, J.; Choi, I.H.; Cheon, J. Development of water-soluble single-crystalline $\mathrm{TiO}_{2}$ nanoparticles for photocatalytic cancer-cell treatment. Small 2007, 3, 850-853. [CrossRef] [PubMed]

18. Ohko, Y.; Utsumi, Y.; Niwa, C.; Tatsuma, T.; Kobayakawa, K.; Satoh, Y.; Kubota, Y.; Fujishima, A. Self-sterilizing and self-cleaning of silicone catheters coated with $\mathrm{TiO}_{2}$ photocatalyst thin films: A preclinical work. J. Biomed. Mater. Res. 2001, 58, 97-101. [CrossRef] 
19. Suketa, N.; Sawase, T.; Kitaura, H.; Naito, M.; Baba, K.; Nakayama, K.; Wennerberg, A.; Atsuta, M. An antibacterial surface on dental implants, based on the photocatalytic bactericidal effect. Clin. Implant Dent. Relat. Res. 2005, 7, 105-111. [CrossRef] [PubMed]

20. Kim, D.S.; Kwak, S.-Y. Photocatalytic inactivation of E. coli with a mesoporous $\mathrm{TiO}_{2}$ coated film using the film adhesion method. Environ. Sci. Technol. 2009, 43, 148-151. [CrossRef] [PubMed]

21. Behpour, M.; Mehrzad, M.; Hosseinpour-Mashkani, S.M. $\mathrm{TiO}_{2}$ thin film: Preparation, characterization, and its photocatalytic degradation of basic yellow 28 dye. J. Nanostructures 2015, 5, 183-187.

22. Vera, M.L.; Leyva, G.; Litter, M.I. Simple $\mathrm{TiO}_{2}$ coatings by sol-gel techniques combined with commercial $\mathrm{TiO}_{2}$ particles for use in heterogeneous photocatalysis. J. Nanosci. Nanotechnol. 2017, 17, 4946-4954. [CrossRef]

23. Justicia, I.; Garcia, G.; Vázquez, L.; Santiso, J.; Ordejón, P.; Battiston, G.; Gerbasi, R.; Figueras, A. Self-doped titanium oxide thin films for efficient visible light photocatalysis: An example: Nonylphenol photodegradation. Sens. Actuators B Chem. 2005, 109, 52-56. [CrossRef]

24. Justicia, I.; Ordejón, P.; Canto, G.; Mozos, J.L.; Fraxedas, J.; Battiston, G.A.; Gerbasi, R.; Figueras, A. Designed self-doped titanium dioxide thin films for efficient visible-light photocatalysis. Adv. Mater. 2002, 14, 1399-1402. [CrossRef]

25. Yemmireddy, V.K.; Farrell, G.D.; Hung, Y.C. Development of titanium dioxide $\left(\mathrm{TiO}_{2}\right)$ nanocoatings on food contact surfaces and method to evaluate their durability and photocatalytic bactericidal property. J. Food Sci. 2015, 80, N1903-N1911. [CrossRef] [PubMed]

26. Sopyan, I.; Watanabe, M.; Murasawa, S.; Hashimoto, K.; Fujishima, A. A film-type photocatalyst incorporating highly active $\mathrm{TiO}_{2}$ powder and fluororesin binder: Photocatalytic activity and long-term stability. J. Electroanal. Chem. 1996, 415, 183-186. [CrossRef]

27. Lin, H.; Xu, Z.; Wang, X.; Long, J.; Su, W.; Fu, X.; Lin, Q. Photocatalytic and antibacterial properties of medical-grade PVC material coated with $\mathrm{TiO}_{2}$ film. J. Biomed. Mater. Res. Part B Appl. Biomater. 2008, 87, 425-431. [CrossRef] [PubMed]

28. Pal, S.; Contaldi, V.; Licciulli, A.; Marzo, F. Self-cleaning mineral paint for application in architectural heritage. Coatings 2016, 6, 48. [CrossRef]

29. Gunda, N.S.K.; Singh, M.; Norman, L.; Kaur, K.; Mitra, S.K. Optimization and characterization of biomolecule immobilization on silicon substrates using (3-aminopropyl)triethoxysilane (APTES) and glutaraldehyde linker. Appl. Surf. Sci. 2014, 305, 522-530. [CrossRef]

30. Landoulsi, J.; Genet, M.J.; Kirat, K.E.; Richard, C.; Pulvin, S.; Rouxhe, P.G. Silanization with APTES for controlling the interactions between stainless steel and biocomponents: Reality vs. expectation. Biomater. Phys. Chem. 2011, 5, 99-126.

31. Li, G.; Yang, P.; Qin, W.; Maitz, M.F.; Zhou, S.; Huang, N. The effect of coimmobilizing heparin and fibronectin on titanium on hemocompatibility and endothelialization. Biomaterials 2011, 32, 4691-4703. [CrossRef] [PubMed]

32. Badv, M.; Jaffer, I.H.; Weitz, J.I.; Didar, T.F. An omniphobic lubricant-infused coating produced by chemical vapor deposition of hydrophobic organosilanes attenuates clotting on catheter surfaces. Sci. Rep. 2017, 7, 11639. [CrossRef] [PubMed]

33. Villegas, M.; Cetinic, Z.; Shakeri, A.; Didar, T.F. Fabricating smooth PDMS microfluidic channels from low-resolution 3D printed molds using an omniphobic lubricant-infused coating. Anal. Chim. Acta 2018, 1000, 248-255. [CrossRef] [PubMed]

34. Didar, T.F.; Cartwright, M.J.; Rottman, M.; Graveline, A.R.; Gamini, N.; Watters, A.L.; Leslie, D.C.; Mammoto, T.; Rodas, M.J.; Kang, J.H.; et al. Improved treatment of systemic blood infections using antibiotics with extracorporeal opsonin hemoadsorption. Biomaterials 2015, 67, 382-392. [CrossRef] [PubMed]

35. Didar, T.F.; Tabrizian, M. Generating multiplex gradients of biomolecules for controlling cellular adhesion in parallel microfluidic channels. Lab Chip 2012, 12, 4363-4371. [CrossRef] [PubMed]

36. Didar, T.F.; Bowey, K.; Almazan, G.; Tabrizian, M. A miniaturized multipurpose platform for rapid, label-free, and simultaneous separation, patterning, and in vitro culture of primary and rare cells. Adv. Healthc. Mater. 2014, 3, 253-260. [CrossRef] [PubMed]

37. Shakeri, A.; Sun, N.; Badv, M.; Didar, T.F. Generating 2-dimensional concentration gradients of biomolecules using a simple microfluidic design. Biomicrofluidics 2017, 11. [CrossRef] [PubMed] 
38. Kim, W.J.; Kim, S.; Lee, B.S.; Kim, A.; Ah, C.S.; Huh, C.; Sung, G.Y.; Yun, W.S. Enhanced protein immobilization efficiency on a $\mathrm{TiO}_{2}$ surface modified with a hydroxyl functional group. Langmuir 2009, 25, 11692-11697. [CrossRef] [PubMed]

39. Cheng, F.; Sajedin, S.M.; Kelly, S.M.; Lee, A.F.; Kornherr, A. UV-stable paper coated with APTES-modified P25 $\mathrm{TiO}_{2}$ nanoparticles. Carbohydr. Polym. 2014, 114, 246-252. [CrossRef] [PubMed]

40. Gong, Z.; Tang, D.; Guo, Y. The fabrication and self-flocculation effect of hybrid $\mathrm{TiO}_{2}$ nanoparticles grafted with poly(N-isopropylacrylamide) at ambient temperature via surface-initiated atom transfer radical polymerization. J. Mater. Chem. 2012, 22, 16872. [CrossRef]

41. Xu, Z.; Shang, J.; Liu, C.; Kang, C.; Guo, H.; Du, Y. The preparation and characterization of $\mathrm{TiO}_{2}$ ultrafine particles. Mater. Sci. Eng. B 1999, 63, 211-214. [CrossRef]

42. Yu, J.-G.; Yu, H.-G.; Cheng, B.; Zhao, X.-J.; Yu, J.C.; Ho, W.-K. The effect of calcination temperature on the surface microstructure and photocatalytic activity of $\mathrm{TiO}_{2}$ thin films prepared by liquid phase deposition. J. Phys. Chem. B 2003, 107, 13871-13879. [CrossRef]

43. Lopez, N.; Nørskov, J.K.; Janssens, T.V.W.; Carlsson, A.; Puig-Molina, A.; Clausen, B.S.; Grunwaldt, J.-D. The adhesion and shape of nanosized $\mathrm{Au}$ particles in a $\mathrm{Au} / \mathrm{TiO}_{2}$ catalyst. J. Catal. 2004, 225, 86-94. [CrossRef]

44. Kang, I.-C.; Zhang, Q.; Yin, S.; Sato, T.; Saito, F. Preparation of a visible sensitive carbon doped $\mathrm{TiO}_{2}$ photo-catalyst by grinding $\mathrm{TiO}_{2}$ with ethanol and heating treatment. Appl. Catal. B Environ. 2008, 80, 81-87. [CrossRef]

45. Yamada, K.; Yamane, H.; Matsushima, S.; Nakamura, H.; Ohira, K.; Kouya, M.; Kumada, K. Effect of thermal treatment on photocatalytic activity of $\mathrm{N}$-doped $\mathrm{TiO}_{2}$ particles under visible light. Thin Solid Films 2008, 516, 7482-7487. [CrossRef]

46. Widegren, J.; Bergström, L. The effect of acids and bases on the dispersion and stabilization of ceramic particles in ethanol. J. Eur. Ceram. Soc. 2000, 20, 659-665. [CrossRef]

47. Kardys, A.Y.; Bharali, D.J.; Mousa, S.A. Amino-functionalized silica nanoparticles: In vitro evaluation for targeted delivery and therapy of pancreatic cancer. J. Nanotechnol. 2013, 2013, 768724. [CrossRef]

48. Chen, L.-X.; Zheng, J.-N.; Wang, A.-J.; Wu, L.-J.; Chen, J.-R.; Feng, J.-J. Facile synthesis of porous bimetallic alloyed PdAg nanoflowers supported on reduced graphene oxide for simultaneous detection of ascorbic acid, dopamine, and uric acid. Analyst 2015, 140, 3183-3192. [CrossRef] [PubMed]

49. Praveen, P.; Viruthagiri, G.; Mugundan, S.; Shanmugam, N. Structural, optical and morphological analyses of pristine titanium di-oxide nanoparticles-Synthesized via sol-gel route. Spectrochim. Acta Part A Mol. Biomol. Spectrosc. 2014, 117, 622-629. [CrossRef] [PubMed]

50. Lu, H.B.; Zhou, Y.Z.; Vongehr, S.; Tang, S.C.; Meng, X.K. Effects of hydrothermal temperature on formation and decoloration characteristics of anatase $\mathrm{TiO}_{2}$ nanoparticles. Sci. China Technol. Sci. 2012, 55, 894-902. [CrossRef]

51. Watson, S.; Beydoun, D.; Scott, J.; Amal, R. Preparation of nanosized crystalline $\mathrm{TiO}_{2}$ particles at low temperature for photocatalysis. J. Nanoparticle Res. 2004, 6, 193-207. [CrossRef]

52. Chen, Y.F.; Lee, C.Y.; Yeng, M.Y.; Chiu, H.T. The effect of calcination temperature on the crystallinity of $\mathrm{TiO}_{2}$ nanopowders. J. Cryst. Growth 2003, 247, 363-370. [CrossRef]

53. Chellappa, M.; Anjaneyulu, U.; Manivasagam, G.; Vijayalakshmi, U. Preparation and evaluation of the cytotoxic nature of $\mathrm{TiO}_{2}$ nanoparticles by direct contact method. Int. J. Nanomed. 2015, 10, 31-41.

54. Socrates, G. Infrared and Raman Characteristic Group Frequencies, 3rd ed.; John Wiley \& Sons Ltd.: Chichester, UK, 2001.

55. Olurode, K.; Neelgund, G.M.; Oki, A.; Luo, Z. A facile hydrothermal approach for construction of carbon coating on $\mathrm{TiO}_{2}$ nanoparticles. Spectrochim. Acta Part A Mol. Biomol. Spectrosc. 2012, 89, 333-336. [CrossRef] [PubMed]

56. Kango, S.; Kalia, S.; Celli, A.; Njuguna, J.; Habibi, Y.; Kumar, R. Surface modification of inorganic nanoparticles for development of organic-inorganic nanocomposites-A review. Prog. Polym. Sci. 2013, 38, 1232-1261. [CrossRef]

57. Yoshimitsu, Z.; Nakajima, A.; Watanabe, T.; Hashimoto, K. Effects of surface structure on the hydrophobicity and sliding behavior of water droplets. Langmuir 2002, 18, 5818-5822. [CrossRef]

58. Han, J.-B.; Wang, X.; Wang, N.; Wei, Z.-H.; Yu, G.-P.; Zhou, Z.-G.; Wang, Q.-Q. Effect of plasma treatment on hydrophilic properties of $\mathrm{TiO}_{2}$ thin films. Surf. Coat. Technol. 2006, 200, 4876-4878. [CrossRef] 
59. Nie, X.; Zhuo, S.; Maeng, G.; Sohlberg, K. Doping of $\mathrm{TiO}_{2}$ polymorphs for altered optical and photocatalytic properties. Int. J. Photoenergy 2009, 2009, 1-22. [CrossRef]

60. Ren, R.; Yang, Z.; Shaw, L.L. Polymorphic transformation and powder characteristics of $\mathrm{TiO}_{2}$ during high energy milling. J. Mater. Sci. 2000, 35, 6015-6026. [CrossRef]

61. Mei, Z.-G.; Wang, Y.; Shang, S.; Liu, Z.-K. First-principles study of the mechanical properties and phase stability of $\mathrm{TiO}_{2}$. Comput. Mater. Sci. 2014, 83, 114-119. [CrossRef]

62. Hanaor, D.A.H.; Sorrell, C.C. Review of the anatase to rutile phase transformation. J. Mater. Sci. 2011, 46, 855-874. [CrossRef]

63. Zhao, J.; Milanova, M.; Warmoeskerken, M.M.C.G.; Dutschk, V. Surface modification of $\mathrm{TiO}_{2}$ nanoparticles with silane coupling agents. Colloids Surfaces A Physicochem. Eng. Asp. 2012, 413, 273-279. [CrossRef]

(C) 2018 by the authors. Licensee MDPI, Basel, Switzerland. This article is an open access article distributed under the terms and conditions of the Creative Commons Attribution (CC BY) license (http:/ / creativecommons.org/licenses/by/4.0/). 